\title{
Results of the 1997-1998 Multi-country FAO Activity on Containment and Control of the Western Corn Rootworm, Diabrotica virgifera virgifera LeConte, in Central Europe
}

\author{
C. R. EDWARDS ${ }^{1,2}$, J. IGRC BARCIC ${ }^{3}$, H. BERBEROVIC ${ }^{4}$, H. K. BERGER ${ }^{5}$, \\ H. FESTIC ${ }^{6}$, J. KISS ${ }^{7}$, G. PRINCZINGER ${ }^{8}$, G. G. M. SCHULTEN ${ }^{9}$ and I. VONICA ${ }^{10}$ \\ ${ }^{1}$ Department of Entomology, Purdue University, W. Lafayette, Indiana 47907-1158, USA \\ ${ }^{3}$ Faculty of Agriculture, University of Zagreb, Svetosimunska cesta 25, 10000 Zagreb, Croatia \\ ${ }^{4}$ Institute of Agriculture, Ul. Obala Zmaja od Bosne br. 10, Tuzla, Bosnia-Herzegovina \\ ${ }^{5}$ Federal Office and Research Center of Agriculture, Spargelfeldstr. 191, A-1226 Vienna, Austria \\ ${ }^{6}$ Faculty of Agriculture, University of Sarajevo, Zmaja od Bosne 8, Bosnia-Herzegovina \\ ${ }^{7}$ Department of Plant Protection, Gödöllő University of Agricultural Sciences, \\ H-2103 Gödöllö, Pater K. utca 1, Hungary \\ ${ }^{8}$ Plant Protection and Agroenvironment-Management Department, Ministry of Agriculture, \\ H-1055 Budapest, Kossuth L. tér 11, Hungary \\ ${ }^{9}$ Plant Protection Service, FAO United Nations, Viale delle Terme di Caracalla, 00100 Rome, Italy \\ ${ }^{10}$ Central Laboratory of Phytosanitary Quarantine, Ministry of Agriculture and Food, \\ Sos. Afumati 11, 72964 Bucharest, Romania
}

\begin{abstract}
A Food and Agriculture Organization of the United Nations Technical Cooperation Programme (TCP) was undertaken on the western corn rootworm (WCR) in 1997-1998 to establish a permanent monitoring network, evaluate a containment and control program, test the feasibility and effectiveness of using a Slam ${ }^{\circledR}$-based areawide pest management program, develop training materials, and conduct a risk assessment of the potential for WCR spread and establishment in other areas of Europe. TCP countries were Bosnia-Herzegovina, Croatia, Hungary, and Romania. Bulgaria and Yugoslavia cooperated as unofficial TCP members. The data from the permanent monitoring network showed that the WCR had spread over an area of about $105,600 \mathrm{~km}^{2}$ in Central Europe and that economic populations had developed on 14,000 $\mathrm{km}^{2}$ in Yugoslavia through 1998. The containment and control trapping program, although designed to determine the feasibility of restricting the establishment of WCR beetles in an area, did not prove to be successful due to the number of WCR beetles encountered and their rapid movement into previously uninfested areas. The areawide pest management activity showed that the semiochemical Slam was highly efficacious against WCR beetles with residual activity for up to 2 weeks, thus making it a cost-effective alternative to other controls. Also, investigations showed that WCR will continue to spread and establish in other parts of Europe.
\end{abstract}

Key words: Western corn rootworm, Diabrotica virgifera virgifera.

The western corn rootworm (WCR), Diabrotica virgifera virgifera LeConte, has the potential to cause extensive losses in corn production in Central Europe. Yield losses approaching those seen in the USA, approximately 2 t/ha (Edwards et al., 1998), have been reported within an area of approximately $14,000 \mathrm{~km}^{2}$ in Yugoslavia through 1998 (I. Sivcev, personal communication). This is up from $12,000 \mathrm{~km}^{2}$ in 1997 . Since its discovery in a cornfield at Surcin, Yugoslavia, in 1992 (Baca, 1993), the WCR has spread over approximately 105,600 km² of Yugoslavia, 61,400 km²; Bosnia-Herzegovina, 1,500 km²; Croatia, 10,500 km²; Hungary, 20,000 km²; and Romania, 12,000 km² (Edwards, 1999) (Fig. 1). It was trapped in 1998 in the northwestern corner of Bulgaria $\left(200 \mathrm{~km}^{2}\right)$ near the 


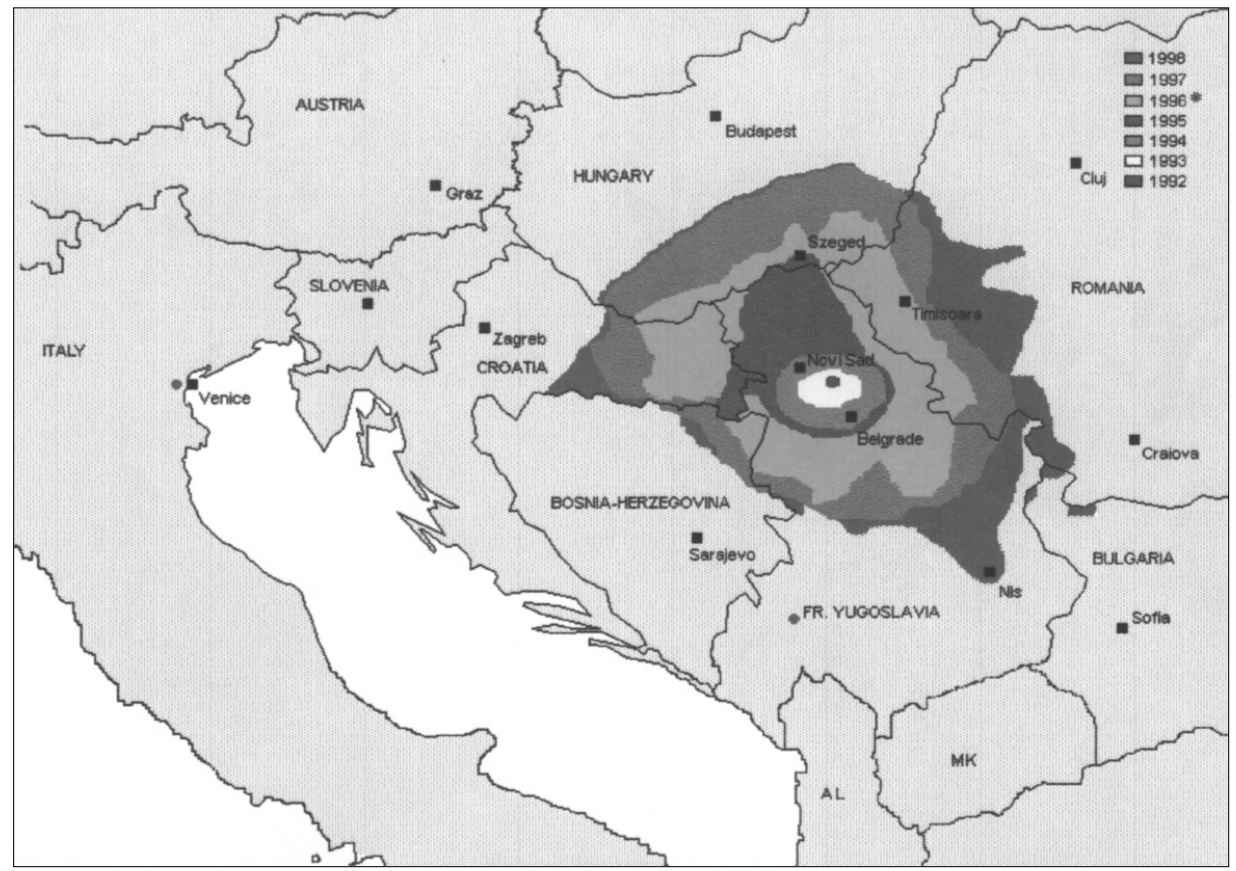

Fig. 1. Spread of Western Corn Rootworm in Europe from 1992-1998

(by Gy. Barna and C. R. Edwards based on data from Igrc-Barcic, Festic, Furlan, Ilovai, Ivanova, Maceljski, Princzinger, Sivcev and Vonica)

Danube River bordering Romania and on the Bulgarian side next to the Yugoslavian border. Additionally, a small number of beetles were trapped in an $11 \mathrm{~km}^{2}$ area in 1998 near the Marco Polo Airport, Venice, Italy, and near the city of Bijelo Polje in Montenegro (near a railroad line with direct link to Belgrade).

Activities with the Food and Agriculture Organization (FAO) of the United Nations through a Technical Cooperation Programme (TCP/RER/6712) were undertaken in 1997-1998 to establish a permanent monitoring network, evaluate a containment and control program, test the feasibility and effectiveness of using a Slam ${ }^{\circledR}$-based (Micro Flo Company, Lakeland, Florida) areawide pest management program, develop training materials, and conduct a risk assessment of the potential for the spread and establishment in other areas of Europe. One or more of these activities were conducted in Bosnia-Herzegovina, Croatia, Hungary, and Romania, as well as in the unofficial TCP countries of Yugoslavia and Bulgaria. 


\section{Materials and Methods}

1.) Permanent monitoring network - In 1997, Hungarian pheromone (8methyl-2-decyl-propanoate) traps (Tóth et al., 1996) were placed in 10, 16, and 27 permanent locations in Croatia, Hungary, and Romania, respectively, to determine population levels over time (59 traps were established in Bosnia-Herzegovina in 1997, but were not designated as permanent traps). The traps were placed at 10,10, 16, and 27 permanent locations in Bosnia-Herzegovina, Croatia, Hungary, and Romania, respectively, in 1998. Traps were monitored at intervals from weekly to monthly, depending on the numbers of WCR caught (the more caught, the more often the traps were monitored). New pheromone traps were placed at each site after approximately 30 days, and between the times of trap replacement WCR's were removed from the sticky surface after counting. The traps were monitored from early July through the middle of September in 1997 and from late June until the beginning of October in 1998. The counts were recorded for each trap, for each sampling period, and the location of the trap and date of counts recorded.

2.) Containment and control program - Hungarian pheromone and Multigard ${ }^{\circledR}$ (Scentry, Billings, Montana) yellow sticky traps were placed in pairs at 4-5 sites along the leading edge of the infestation in Croatia, Hungary, and Romania (Bosnia-Herzegovina did not participate). Both pheromone and Multigard traps were used so as to capture both males and females. The males were attracted to the pheromone, while both females and males were attracted to the Multigard traps. When a catch was recorded on either trap at any location, 12 sets of paired pheromone and Multigard traps, the pair being placed within 5 meters of each other, were placed at 1 kilometer increments radiating out in 4 directions (up, down, left, and right as one views the traps as if standing in Yugoslavia and looking toward the trap within their country) from the original pair (Edwards et al., 1998). This arrangement allowed for 3 new pairs of traps over a distance of 3 kilometers beyond the original trap.

If the second set of traps or any original set of traps recorded catches, additional pairs of traps were placed at 1-kilometer increments radiating out until no more WCR's were caught or until the middle of September. Each trap pair was checked every 7-10 days and the results recorded on a standardized record form using the code developed for this project. All traps were changed at intervals of 30 days, except for traps placed out after August 9; they were not replaced, but were monitored until mid September. No trap pair was replaced more than 3 times during the trap-monitoring period. Additional traps were added using the same arrangement when catches were made on other traps within the trapping grid. Paired traps were only added in one or more of the four directions if other traps were not already in place in that direction.

This trapping activity was designed to determine the feasibility of trapping out as many WCR beetles as possible. It was hoped that it would be possible to show that the buildup of a WCR population in a given area could be slowed or possibly stopped using this trapping method. This would have the greatest use in areas where the beetle is isolated, such as valleys, or where there are barriers to its movement, such as mountains. This management program could be used in certain regions of all participating countries, but 
would probably have the greatest application in the Croatian valleys leading to the western part of the country and the Cris, Mures, and Timis river valleys intersecting with the Carpathian Mountains in Romania.

3.) Slam-based areawide pest management program - Slam is a semiochemical insecticide bait containing WCR feeding stimulants, cucurbitacins; a small amount of the toxic insecticide carbaryl; and inert ingredients.

In 1997 an abbreviated study was conducted in 2 fields, 20 and 40 ha, in southern Hungary near Szeged and Csanádpalota, respectively (companion untreated fields were included in the study). Before applying Slam, the aircraft, a Cessna C-188, was modified based on the protocol, and a trial application was made over water sensitive paper (CibaGeigy ${ }^{\circledR}$ ) placed on flat ground. This was done to determine spray pattern, droplets $/ \mathrm{cm}^{2}$, and droplet size in microns. On flat ground, droplet size of 600 microns was achieved with droplet distribution of $5 / 5 \mathrm{~cm}^{2}$. The use of the Cessna allowed for USA application protocols to be used more easily. Also, the experience gained in the adaptation of this sprayplane was fully transferable to UTVA-65 and IAR planes used in Central and Eastern Europe. The application was carried out using the following parameters: air speed $=160 \mathrm{~km} / \mathrm{h}$, spray boom width $=12 \mathrm{~m}$, and spray rate $=9.7 \mathrm{l} / \mathrm{ha}$. Ten RSZ X-09 nozzles, at an angle of 90 degrees fitted with Spray Systems ${ }^{\circledR}$ D-6 plates and applied at a pressure of $2.82 \mathrm{~kg} / \mathrm{cm}^{2}$, were used. The spray was applied at a rate of $9.7 \mathrm{l} / \mathrm{ha}$, containing $420 \mathrm{~g} / \mathrm{ha}$ Slam, $0.1 \%$ by volume Windbrake ${ }^{\circledR}$ (drift retardant, but used to improve deposition of spray on leaves), and $0.1 \%$ by volume Tinopal $\mathrm{CBX}^{\circledR}$ (fluorescent dye). The final spray, when applied to the corn, registered approximately 1 droplet $/ 6.45 \mathrm{sq}$. $\mathrm{cm}$ as called for in the protocol.

In 1998, according to the areawide management concept, the plan was to initiate the program when beetles were present, and about $10 \%$ of the females were gravid. This occurred in early August in 1998 at the Hungarian study site. The study was conducted on 1,800 ha of seed corn in southern Hungary near Mezőhegyes. Before applying the Slam, the aircraft, an M-18 Dromader was modified based on the established protocol and a trial application was made over water sensitive paper placed on flat ground. This was done to determine the spray pattern, droplets per $\mathrm{cm}^{2}$, and droplet size in microns. On flat ground a droplet size of 600 microns was achieved with distribution of droplets of $6.1 / 6.25 \mathrm{~cm}^{2}$

The application was carried out using the following parameters: air speed $=170$ $\mathrm{km} / \mathrm{h}$, spray boom width $=22 \mathrm{~m}$, and spray rate $=9 \mathrm{l} / \mathrm{ha}$. Fourteen RSZ X-09 nozzles, at an angle of 90 degrees fitted with Spray Systems D-6 plates were used. The application pressure was $2.0-2.5 \mathrm{~kg} / \mathrm{cm}^{2}$. The $9 \mathrm{l} / \mathrm{ha}$ contained $420 \mathrm{~g} / \mathrm{ha}$ Slam, $0.1 \%$ by volume Windbrake, and $0.1 \%$ by volume Tinopal CBX. The final spray, when applied to the corn, registered approximately 1 droplet/6,25 $\mathrm{cm}^{2}$. The flight height was $1-2 \mathrm{~m}$. The date of treatment was 13 August 1998.

4.) Risk assessment of the potential for the spread and establishment in other areas of Europe - The FAO Agromet Group in Research, Extension and Training Division; Environmental and Natural Resources Service (SDRN) and Land and Water Development Division; Soils Resources Management and Conservation Service (AGLS) 
collected data from studies in the USA on the impact of various parameters on the establishment and survival of WCR. Each parameter was evaluated as a single factor then combined with the other parameters, each carrying different weights based on their level of importance, to determine the overall effect on the potential for establish of WCR in the various regions of Europe.

\section{Results and Discussion}

1.) Permanent monitoring network - Croatia - Monitoring started on July 1 . The main flight of WCR beetles in 1997 occurred from July 10 to September 20, with the first appearance July 4 and the last October 3. A dense chain of paired traps (pheromone and Multigard) at least $100 \mathrm{~m}$ apart was placed from the Yugoslavian border toward the west. Additional traps were placed even further to the west along the road to Zagreb, as well as near the new WCR front line as new WCR trap catches were observed. All together, 134 sites were monitored. Ten monitoring traps were designated as the permanent monitoring network traps. For all traps monitored in 1997, 3,227 beetles were caught $(3,141$ on pheromone and 86 on Multigard traps). Most, 2,472, were caught in Vukovarsko-srijemska zupanija (2,398 on pheromone and 74 on Multigard traps). In the Vukovar region, an average of 13 beetles per trap per day was caught, while 6 per trap per day were caught in the Otok region. The level of catch increase from 1996 (prior to the TCP) to 1997 was three fold. WCR damaged roots, although not at economic levels, were noted in insecticide trials near Otok.

The WCR beetle monitoring activity for 1998 occurred from June 25 to October 7, with the first capture occurring on June 26 (in Tovarnik) and the last October 5. The beetle flight started approximately 7 days earlier and ended 2 days later than in 1997. A dense chain of traps was placed from the Yugoslavian border toward the west in 1998, and each site was at least $100 \mathrm{~m}$ from other sites. Additional traps were placed even further to the west along the road to Zagreb, as well as near the new WCR front line as new WCR trap catches were observed. All together, 90 monitors checked traps at 136 sites. Of these, 62 sites (46\%) were in previously infested areas, 37 sites $(27 \%)$ were situated along the frontline of spread, and 37 sites $(27 \%)$ were placed in previously uninfested territory. On July 28, one beetle was captured in Gornji Varos near the river Sava and the Bosnian border. This was $37 \mathrm{~km}$ west of the point of furthest spread in 1997. Seven days later, one beetle was caught in Nova Gradiska along the highway from Belgrade to Zagreb. This was about $30 \mathrm{~km}$ west from the point of the 1997 WCR spread. As in 1997, ten monitoring traps were designated as the permanent monitoring network traps.

For all traps monitored in $1998,5,933$ beetles were caught $(5,628$ on pheromone and 305 on Multigard traps). As in 1997, most, 4,614 (78\% of total), were caught in Vukovarsko-srijemska County (4416 on pheromone and 198 on Multigard traps). These were registered from 24 trapping sites, while the 2,472 caught in 1997 were from 22 . The level of catch increase from 1997 to 1998 was almost twofold. In the area with the highest population of beetles (Tovarnik), 26 beetles per trap per day were captured from July 9 
to 13 , while approximately the same number, 27 beetles per trap per day, were caught in the first decade of August. It is important to note that the region of Baranya bordering Hungary did not register any WCR beetle catches in 1997, although it was behind the advancing WCR population. This was thought to be due to the 17,000 ha of marshland within this region acting as a barrier to the beetle's movement through this area. However, 394 beetles were captured at 10 sites in this region in 1998 thus indicating that, although slowed by this marshland, the beetle's movement was not totally stopped. WCR damaged roots, although not at economic levels, were noted in insecticide trials near Otok. The average damage rating was 3 using the 1-9 scale as described by Musick and Suttle (1972) with a maximum rating of 5 (ratings of 1-6 in this scale correspond to the 1-3 ratings of the Iowa 1-6 scale, with 3 or below being considered by most as noneconomic). All together, about $10,500 \mathrm{~km}^{2}$ are infested with WCR in Croatia. Approximately 150,000 ha of corn are grown in this area. This area represents about $19 \%$ of the total surface area of Croatia and $42 \%$ of the total corn producing area.

Hungary - In 1997, the establishment of traps was based on "waiting" traps employing Hungarian pheromone traps and "linear" traps using the pheromone and Multigard yellow sticky traps. The waiting traps were established beyond the area of known infestation as part of a forecasting system. The linear traps were placed within and along the front line of the advancing WCR population and included 48 traps, of which 16 were permanent traps. WCR expanded 100-120 km from the southern border of the country through 1997 . More than 3,800 beetles were caught on the various traps across the country. WCR was detected at 83 , or $33 \%$, of the 249 locations throughout Hungary. An average of 47 beetles were caught per trap countrywide.

Of the traps in Csongrád, Békés, Bács-Kiskun, and Baranya Counties of the WCR infested area, 88, 59, 67, and 70\%, respectively, had catches. The traps in Csongrad County caught an average of 115 per trap. Of the three zones, 3,864, 46, and 0 beetles were caught in the southern, middle, and northern zones, respectively. The permanent monitoring network traps caught an average of 150 beetles per trap, ranging from 1 to 807 . These traps caught a total of 2,395 beetles. Within Hungary, about $20,000 \mathrm{~km}^{2}$ were infested in 1997. In the Szeged area, larval damage to roots was noted in 1997. This damage, however, was not at economic levels. While monitoring for beetles in 1997, WCR adults were observed on corn, sunflower, beans, soybean, alfalfa, squash, ragweed, and pigweed. Feeding damage, although not at economic levels, was noted on the first three.

In 1998, beetles were first observed on June 25. As in 1997, the establishment of traps in 1998 was based on "waiting" traps employing Hungarian pheromone traps, "linear" traps using pheromone, and "standard" permanent monitoring network traps using both pheromone and Multigard yellow sticky traps. The 78 waiting traps were established beyond the area of known infestation as part of the forecasting system. The linear traps were placed within and along the front line of the advancing WCR population in 8 counties. The 56 linear traps were placed within 7 to $10 \mathrm{~km}$ of each other. Out of the linear traps, 10 had catches.

Pheromone and yellow sticky traps were placed in permanent locations to determine population levels over time. These two trap types were placed within $50 \mathrm{~m}$ of each 
other. Traps were monitored by decade. New traps were placed at each site after 30 days, and between the times of trap placement WCR beetles were removed from the sticky surface after counting. The traps were monitored from early July through the end of September. The counts were recorded for each trap, for each sampling period, and the location of traps and date of counts noted. A total of 1,874 (1,790 on pheromone and 84 on Multigard traps for an average of 112 and 5 per trap, respectively) were captured in 1998 at 16 locations in Hungary.

Thirteen of 16 permanent trap sites had beetle catches. These 13 sites were in Csongrád, Békés, Bács-Kiskun, and Baranya Counties. None were observed, however, in Pest and Tolna Counties. The pheromone traps in Csongrád County caught an average of 230 beetles per trap, while the Multigard traps caught an average of 8 per trap. In Békés, Bács-Kiskun, and Baranya Counties these figures were 107 and 1; 120 and 13; and 63 and 4, respectively. The permanent monitoring network traps caught and average of 74 beetles per pheromone trap and 4 per Multigard trap. The trap catch range was from 0 to 918 for pheromone and 0 to 39 for Multigard traps. Within Hungary, about $30,000 \mathrm{~km}^{2}$ were infested in 1998. In the Szeged area, larval damage to roots was noted in 1998, as in 1997. This damage, however, was not at economic levels. From 1996 through 1998, WCR expanded its range $120 \mathrm{~km}$ from the southern borders with Yugoslavia, Romania, and Croatia.

Romania - In 1997, monitoring started on July 4, with 240 pheromone traps (both Romanian and Hungarian types) being placed in four districts (Arad, Timis, CarasSeverin, and Bihor, hereafter referred to as districts 1-4) of the western region. Starting in August, 316 Multigard yellow sticky traps were added to those of the expanded pheromone-trapping network, which by August totaled 355 pheromone traps, and four additional districts (Mehedinti, Alba, Hunedoara, and Dolj, hereafter referred to as districts 5-8) were included in the network. During the course of the trapping period, 39,897 WCR beetles were trapped on pheromone (36,161 or 91\%) and Multigard traps (3,736 or 9\%).

In July, 2,696 beetles were caught on the pheromone traps in districts $1-4$. No Multigard traps were in place at this time, and no traps were in districts 5-8. The 296 pheromone traps in August and 335 in September in districts 1-4 caught 15,835 and 17,494 beetles, respectively. During this same period, the 296 and 335 Multigard traps caught 2,544 and 1,192 beetles, respectively. In August, the first beetles were observed in Mehedinti, one of 5-8 districts. The 20 pheromone traps in this district caught 23 beetles. In September, this increased to 113 beetles on 24 pheromone traps, but no beetles were caught on the other 39 pheromone traps in the other three districts of districts 5-8. The 20 Multigard traps, which were only placed in Mehedinti of districts 5-8 in August and September, did not catch any beetles.

In the permanent monitoring network, 27 Hungarian pheromone traps were included. The traps were placed in the following districts: Alba, Arad, Bihor, CarasSeverin, Hunedoara, Mehedinti, Timis, and Dolj. No beetles were captured on 10 of the traps. No captures were recorded in Alba, Bihor, Hunedoara, and Dolj districts, and 2 traps of 5 in Arad did not record captures. The highest average number of beetles caught per pheromone trap for a district over the trapping period July through September 15 was 
880 in the Caras-Severin district. The pheromone trap at Naidas Vama caught the highest number overall for a single trap, 1,681 beetles.

Monitoring in 1998 started on June 25 with 207 paired Hungarian pheromone and Multigard yellow sticky traps being placed in 11 districts (Alba, Arad, Bihor, CarasSeverin, Dolj, Gorj, Hunedoara, Mehedinti, Olt, Satu-Mare, and Timis, hereafter referred to as districts 1-11) of the western, northwestern, and southwestern regions of Romania. Traps were also concentrated along the Mures, Danube, and Timis rivers. The two traps of each pair were placed within 5 to $10 \mathrm{~m}$ of each other. Additional paired traps were added during the trapping period with 240 paired traps being operational in August. The distance between the paired traps was from 5 to $30 \mathrm{~km}$. Fewer traps spread over a greater distance were installed in previously infested areas and in new monitoring areas. Traps were more concentrated along and shortly beyond the edge of the infestation. The pheromone traps were changed monthly and the yellow sticky traps bimonthly. During the course of the trapping period, 26,745 WCR beetles were trapped on pheromone $(22,093$ or $83 \%)$ and Multigard traps $(4,652$ or $17 \%)$.

In the final 6 days of June, 4 beetles were caught on 207 pheromone traps ( 0 caught on 207 Multigard traps) in 11 counties. Through July 5,003 and 1,376 beetles were caught on 215 pheromone and 215 Multigard traps, respectively. In August, 12,637 and 2,504 beetles were captured on 240 traps each of pheromone and Multigard, respectively. The beetle trap catch numbers fell off to 4,184 and 772 for the two trap types, respectively, in September. In June, the first catches in Hunedoara County were recorded. No beetles were caught on either pheromone or Multigard traps in Alba, Dolj, Gorj, Olt, and Satu-Mare Counties.

In the permanent monitoring network, 27 paired pheromone and Multigard traps were included. The traps were placed in the following districts: Alba, Arad, Bihor, CarasSeverin, Hunedoara, Mehedinti, Timis, and Dolj. No beetles were captured at 8 locations of the paired traps. When looked at singly (not as a pair), 9 pheromone and 11 Multigard traps did not catch beetles. No captures were recorded in Alba and Dolj districts, and 2 trapping sites out of 5 in Arad, 1 out of 2 in Bihor, and 1 out of 2 in Hunedoara. The highest average number of beetles caught per pheromone and Multigard traps, for those recording captures over the trapping period (late June through September), was 476 and 126, respectively, in the Caras-Severin district. The overall average number of beetles captured on traps recording captures was 201 and 42, respectively, for pheromone and Multigard traps.

Bosnia-Herzegovina - In 1997, Hungarian pheromone traps were placed in the cantons (regions) of Tuzla-Posavina and Zenica-Doboj beginning on August 10. WCR's were caught only in the Tuzla-Posavina canton, which is the largest corn-producing canton in Bosnia-Herzegovina. In this region, 26 of 60 traps (43\%) caught 326 beetles. The greatest number of beetles was caught near Brka (193). Traps at two sites in this region, Dobo-Istok and Gracanica, did not record beetles. Two other locations, Srebrenik and Gradacac, had catches at one of two sites each. Beetles were not trapped in the Zenica-Doboj canton.

In 1998, Hungarian pheromone and Multigard yellow sticky traps were received on June 15 and placed in the cantons (regions) of Sava (Posavski), Tuzla-River Drina 
(Tuzlansko-Podrinjski), and River Una-River Sava (Unsko-Sanski) at the end of June, beginning of July. The two trap types were set 50 to $100 \mathrm{~m}$ from each other at each of 67 locations. The traps were examined biweekly to weekly (7 locations in Posavski canton, 57 in Tuzlansko-Podrinjski canton, and 3 in Unsko-Sanski canton). After 25 days, the traps were replaced with new traps, thus being replaced four times. Observations were made over a three-month period. During this period, 55 out of 67 trapping sites, or $82 \%$, recorded WCR catches. A total of 828 beetles were caught on pheromone traps $(30 \%$ of beetles caught in July, 65\% in August, and 5\% in September) and 35 on Multigard traps. The first beetle caught was trapped on July 5. In the Posavski canton community of Orasje, the 4 pheromone traps caught significantly more beetles than in 1997. All 3 pheromone traps in the Odzak community caught beetles. This area did not have traps in 1997. In all, 219 beetles were captured on pheromone traps in Posavski canton. Some beetles were also caught on Multigard traps in Orasje, but none were caught in Odzak. A total of 29 beetles were captured on Multigard traps in Orasje. No larval damage to roots was noted in the Posavski canton, but some silk damage was observed in Orasje.

In the Tuzlansko-Podrinjski canton, 10 out of 14 communities had pheromone traps that captured WCR beetles. A total of 609 beetles were caught on the 57 pheromone traps in this canton. The highest number was caught in the communities of Brcko, Celic, and Kalesija where 207, 156, and 100, respectively, were caught. WCR beetles were only caught in Multigard traps in the communities of Brcko, Brcko-Ravne, Kalesija, and Sapna. In the Tuzlansko-Podrinjski canton, 6 beetles were captured on 57 Multigard traps. The total surface area of the infested communities in this canton is $1,516 \mathrm{~km}^{2}$, while the uninfested area equals $1,533 \mathrm{~km}^{2}$. Corn is grown on 15,000 to 18,000 ha annually. No root or silk damage was noted. In this area the spread is along the Orasje-Tuzla road and upstream along the River Drina. It is thought that the reason the insect has not been detected in some areas is due to the high elevation of Majevica Mountains. The beetle has not been detected in the canton, Unsko-Sanski.

Non-TCP Countries - Status of WCR in other countries: Austria: Five Hungarian pheromone traps were placed at each of 11 sites (a total of 55 traps) along the eastern side of Austria in 1998. The five traps at each site were arranged in the pattern of a cross in cornfields. The traps were 500 to $1,000 \mathrm{~m}$ from each other. The trap grouping furthest to the south was near Bad Radkersbrug, which is close to the border with Slovenia and not too far from Croatia, and near the border crossing with Hungary in the north at Deutschkreutz. The traps were placed in corn starting on July 1 and were monitored every 7 to 10 days until August 31. Traps were replaced every 2 weeks. None of the traps captured WCR beetles in 1998 .

Bulgaria: Monitoring for WCR beetles in Bulgaria from 1995 through 1997 resulted in no beetle catches (1995-1996 used cucurbitacin traps and 1997 used Romanian pheromone traps). Purdue University, W. Lafayette, Indiana, USA, and the Federal Office and Research Center of Agriculture, Vienna, Austria initially supplied cucurbitacin trap materials. In 1998 Hungarian pheromone and Multigard traps were supplied by FAO. About 220 pheromone and 180 Multigard traps were placed at 51 sites along the northern and western borders of Bulgaria beginning on July 10-12, 1998. Phytosanitary inspectors checked these traps from 1 to 2 times each week. The first WCR beetles caught ( 3 total) 
in Bulgaria were captured on August 7, 1998 with the last being caught on September 30. The highest total number caught on pheromone traps at a single trapping site was 46 at Bregovo (43 caught at Vrachkatchuka). The highest total number caught on Multigard traps was 12 at Vrachkatchuka (6 at Artchar). Traps were replaced after 30 days. The infested area is about $200 \mathrm{~km}^{2}$ in the northwestern corner of the country. About 300 ha of corn are infested.

Germany: Hungarian pheromone traps were set-up in several locations in the corn growing areas of Germany, but no WCR beetles were caught.

Italy: Following the establishment and spread of WCR in parts of Central Europe, a monitoring network was established in Italy. Hungarian sex pheromone traps of the PANEL and CLOAK (M. Tóth, personal communication) design were used (PANEL design is the Hungarian pheromone trap used by all FAO TCP countries). The monitoring was conducted in the northeastern part of Italy at 20 sites in 1998 (12 sites in 1997, no catches). Each site had from 1 to 10 traps. Traps were placed in cornfields where corn is most often grown in monoculture and near possible areas of WCR entry (airports, customs stations, etc.). In 1998, 7 beetles were captured between July 21 and August 13 in Tessera, a site near the Marco Polo Airport, Venice. It is anticipated that an attempt will be made in 1999 to eradicate the population from the infested area.

Republic of Srpska: WCR beetles were monitored in 1998 in the Republic of Srpska using Hungarian pheromone and Pherocon ${ }^{\circledR}$ AM (Tre'ce' Inc., Salinas, California) yellow sticky traps. The trapping activity was carried out in the region west of the Drina River with 16 locations near Bijeljina, 4 near Zvornik, 3 near Brcko, and 1 at Pelagicevo. In the Doboj and Banjaluka regions, traps were placed at 5 and 6 locations, respectively. Traps were setup beginning July 18 and all were in place by July 29. The traps were placed primarily in cornfields, although one pair was placed in a soybean field in Novo Selo. Initial counts in the region west of the Drina River were made two weeks after establishment of the traps, with follow-up evaluations occurring two weeks following the first counts. The actual number of days between counts varied by as much as four days. In the Doboj region the traps were examined once after four weeks, while in the Banjaluka region they were examined three times.

A total of 2,937 WCR beetles were caught on the traps. Of these, 2,858 were caught on pheromone traps and 80 on yellow sticky traps. The highest number of beetles was trapped in the northeastern part of the country. The highest number caught per day per pheromone trap during the first and second sampling periods was 8 and 3, respectively, in the Bijeljina area. Seventeen beetles were captured on the pheromone trap in the soybean field in Novo Selo. In the Banjaluka region, only 2 beetles were captured with these being found on pheromone traps.

Slovenia: WCR monitoring continued for a second year in northeastern Slovenia. Thirty each of Hungarian pheromone and Multigard yellow sticky traps were placed in pairs, with the pair being $5 \mathrm{~m}$ from each other along the Hungarian and Croatian borders. The trapping pair furthest to the north was at Domanjerevci (in Prekmurje) and the trapping point furthest south was Obreaeje (in Krлko Polje). The traps were distributed using the Universal Transverse Mercator network on July 3 and 6. Trapping site coordinates were 
determined by using a GPS device. The traps were examined every 7 to 9 days until September 9 by five monitors. The pheromone traps were changed once, at the beginning of August, and the yellow sticky traps were changed every 14 days except for the final interval, which was after 3 weeks. No WCR beetles were observed on the traps.

Slovak Republic: For monitoring WCR in 1998, 40 points in 37 places along the southern border of the country were chosen. Both Hungarian pheromone and Multigard yellow sticky traps (provided by FAO, but also ordered some pheromone traps from CHEMOL Rt.) were placed in cornfields, at the railroad border crossing point in SturovoOstrihom, and at the main road to Nove Zamky. Pheromone traps were placed at each sampling point while Multigard traps were placed at 10 monitoring sites. The traps were examined weekly starting the beginning of July. Each trap was changed after 30 days. No WCR beetles were captured in 1998.

Ukraine: In 1996 and 1997, 240 and 160 pheromone traps, respectively, were placed in cornfields, and 835,660 and 748,100 ha of corn were inspected, respectively, for the two years. No WCR beetles were found. No data were provided for 1998.

Yugoslavia: Serbia - Since 1993, monitoring for WCR has been coordinated by the Institute for Plant Protection and Environment. In 1998, 36 plant protection specialists from regional agricultural extension stations located in 30 counties were included in the monitoring campaign. Hungarian pheromone traps (about 900), Multigard yellow sticky traps (about 350), and visual observations were used as methods of detecting the presence of adults. Traps were placed in 430 locations in 1998. Traps were obtained through FAO.

Results of 1998 monitoring showed that WCR beetle dispersal was much slower than in previous years. It is thought that this was the result of hot, dry weather conditions in July and August. The infested area covers about $61,400 \mathrm{~km}^{2}$. In 1998 further spread of adults was registered in a southerly direction. The southern boundaries of the infestation are near Ljubovija in the valley of the river Drina and north of Leskovac near Zajecar. Within the 21 counties where WCR has been trapped, 15 of these counties are $100 \%$ infested. These counties include the following: Severno-backi, Srednje-banatski, Severnobanatski, Juzno-banatski, Zapadno-backi, Juzno-backi, Sremski, Macvanski, Kolubarski, Podunavski, Branicevski, Pomoravski, Moravicki, Rasinski, and Grad Beograd. In 1998 from 0 to 383 beetles were caught per trap per week (average of 160 per trap per week for all traps).

Damage from WCR larval feeding has been observed in an area covering about $14,000 \mathrm{~km}^{2}$, which is slightly larger than in $1997\left(12,000 \mathrm{~km}^{2}\right)$. The area with damage can be defined as between the cities of Sid, Vrbas, Zrenjanin, Vrsac, Pozarevac, and Beograd. Damage was also reported in two locations outside this area, these being Subotica (1 field) and Jagodina (2 fields). The 9 counties with damage include the following: Severno-backi, Srednje-banatski, Juzno-banatski, Juzno-backi, Sremski, Macvanski, Branicevski, Pomoravski, and Grad Beograd.

It is estimated that 45,525 ha of corn were damaged in 1998 in Serbia. This damage occurred in fields of continuous corn. The county with the highest level of damage is Juzno-banatski (34,243 ha). In this county, the greatest damage was observed near Pancevo, where corn is traditionally grown in monoculture. In this area, yield losses 
are estimated from slight to $70 \%$ with an average of about $30 \%$. High numbers of beetles were registered from 4 additional counties. In these counties, damage will likely be seen next year. The population density within the infested area is increasing.

Montenegro - In 1998, monitoring of WCR beetles was organized by the Biotechnical Institute of Podgorica. Corn is grown on 6,000 ha in Montenegro. Hungarian pheromone traps and Multigard yellow sticky traps were placed in 9 locations in the corn growing area. Adults were captured on Hungarian pheromone traps at 3 locations near the city of Bijelo Polje (Sutivan, 1 adult; Unevina, 1 adult; and Zaton, 5 adults). All of these locations are in a valley near a railroad line that runs from Serbia into Montenegro. No adults were captured on the Multigard traps.

2.) Containment and control program - Croatia - In the 1997 trapping for containment and control program, all 5 trapping sites recorded catches and additional traps were placed near the traps in the up, down, left, and right arrangement as originally agreed upon in Szeged, Hungary, in July 1997. The Batrina, Pleternica, Kutjevo, Gornje Predrijevo, and Benicanci trapping locations recorded catches of 1, 7, 2, 2, and 10 beetles, respectively.

In 1998, the trapping sites at Pleternica, Nova Gradiska, Gornji Varos, and Benicanci recorded catches of $6,5,5$, and 14 beetles, respectively.

Hungary - In 1997 trapping for containment and control program in Hungary, 4 of 5 traps recorded catches. Additional traps were placed near those traps with positive catches in the up, down, left, and right arrangement. The H-1, H-2, H-3 and H-5 traps recorded catches of 79, 91, 234, and 52 beetles, respectively. Hungary will monitor traps at 4 of the 51997 trapping for containment and control sites in 1998.

In 1998 trapping for containment and control activity, pheromone and Multigard yellow sticky traps were placed in pairs at five sites along the leading edge of the infestation. Of the five sites, one recorded a positive catch. Additional traps were placed near the trap with a positive catch in the up, down, left, and right arrangement as previously described. The HP-5 trap at Dalmand in Tolna County recorded a catch of 1 beetle. No other beetles were caught.

Romania - In 1997 containment and control program in Romania, traps were located in the districts of Arad, Caras-Severin, and Mehedinti. All 4 traps recorded catches. Additional traps were placed near those traps with positive catches in the up, down, left, and right arrangement. The Arad, Caras-Severin, Mehedinti (Ostrovul Corbului area), and Mehedinti (Garla Mare area) traps recorded catches of 25, 5, 5, and 12 beetles, respectively. These same four sites will be used for the containment and control program in 1998.

The containment and control project was not carried out in $\mathbf{1 9 9 8}$ as in 1997. However, in some areas with marginal WCR populations, especially in river meadows, additional traps were added in a similar arrangement as called for in the containment and control program to try to stop adult dissemination. The data show that the movement was not stopped or even slowed.

3.) Slam-based areawide pest management program - In 1997, WCR pretreatment counts on Hungarian pheromone and Multigard yellow sticky traps at Szeged showed that 854 and 31 beetles were caught, respectively, on the two trap types. Eight, 15, and 22 days following treatment, 1 and 1; 3 and 0 ; and 2 and 0 were caught on the 
two trap types, respectively, over the post treatment time period. The untreated companion field was over $1 \mathrm{~km}$ from the treated field and was not as heavily infested as the treated field. Numbers of WCR beetles caught on traps in this field showed that numbers of beetles were the highest for the first 9 days (40 on 17 pheromone traps and 0 on 17 Multigard traps pre-treatment sampling date, and 30 on 17 pheromone traps and 1 on 17 Multigard traps 8 days after treatment), but dropped off during the last two weeks (13 and 0 , and 3 and 0 for the two trap types for the 15 and 22-day sampling periods).

Pre-treatment counts of WCR on pheromone and Multigard traps at Csanádpalota showed that 1,822 and 88 beetles were caught, respectively, on the two trap types. Eight, 15, and 22 days following treatment, 18 and 5; 6 and 1; and 0 and 1 were caught on the two trap types, respectively, over the post-treatment time period. The untreated companion field was not as heavily infested as the treatment field. Numbers of WCR beetles caught on traps in this field showed that numbers of beetles only remained high for the first 9 days (116 on 9 pheromone traps and 0 on 9 Multigard traps pre-treatment sampling date, and 171 on 9 pheromone traps and 5 on 9 Multigard traps 8 days after treatment), but dropped off during the last two weeks (17 and 0 , and 5 and 1 for the two trap types for the 15 and 22-day sampling periods).

In 1998, WCR pretreatment counts on Hungarian pheromone and Multigard yellow sticky traps at Mezőhegyes showed that 33 and 0.24 beetles per trap were caught, respectively, on the two trap types. On the 5th, 10th, and 15 th days following treatment, 1.16 and $0 ; 2.04$ and 0 ; and 4.28 and 0.08 beetles were caught on the two trap types, respectively, over the post treatment time period. The untreated companion field was over $1 \mathrm{~km}$ from the treated field. Numbers of WCR beetles caught on traps in this field over the four sampling periods were 33.42 and $0.58 ; 31.53$ and $0.58 ; 26.68$ and 0.63 ; and 21.42 and 0.42 . From these data, it is apparent that Slam is highly efficacious against WCR beetles and that under little to no rainfall the application should remain effective for 2 weeks.

4.) Risk assessment of the potential for the spread and establishment in other areas of Europe - The FAO Agromet Group in SDRN and AGLS submitted a preliminary report based on the following parameters: WCR develops if April temperature exceeds $12.8{ }^{\circ} \mathrm{C}$ and average temperature for May, June, and July exceeds $17^{\circ} \mathrm{C}$; diapausing WCR's are assumed to be killed by temperatures below $-10{ }^{\circ} \mathrm{C}$; WCR is assumed to prefer continental climates, Koeppen's D climate; semi-arid and polar climate conditions, Koeppen's B and Koeppen's E climates, respectively, are deleterious to WCR; and October temperatures above $12.8^{\circ} \mathrm{C}$ are deemed to break diapause, resulting in death.

Each parameter was evaluated as a single factor then combined with the other parameters, each carrying different weights based on their level of importance, to determine the overall effect. Overall, data output for several of the parameters appeared to be skewed slightly north of the actual WCR population in the USA (partially in the zone of the northern corn rootworm, Diabrotica barberi Smith and Lawrence). As a result of the above, additional data from the USA on parameters that impact the WCR were given to the Agromet Group and new risk assessment projections were made and a WCR suitability for establishment map was produced (Edwards et al., 1998). 


\section{Conclusions}

Although the area of WCR economic activity in Central Europe is still small, this area is expanding and has reached or almost reached the borders with Bosnia-Herzegovina, Croatia, Hungary, and Romania. It is likely that WCR populations will reach levels that will cause economic losses in these countries within the next 1-3 years.

It is also likely that the WCR will find its way into other areas of Europe based both on the rate and direction of its spread through the infested countries and on the results of studies on the suitability for WCR establishment in other corn-producing areas of Europe by the FAO Agromet Group. Additionally, it does not appear that the spread can be stopped through the application of a containment and control program similar to the one tested as part of the TCP project. It does appear, however, that management activities like the Slam-based areawide WCR adult management program could prove successful in keeping WCR populations in defined, managed areas under control.

\section{Acknowledgements}

This project was made possible through funding provided by FAO and its supporting countries. Also, we would not have been able to carry out and complete this phase of the project without the hard work and dedication of plant protection personnel in the participating countries. Special thanks go to the aerial application experts in Hungary for their work on the Slam-based areawide pest management program. This is a Purdue Agricultural Research Programs Paper No. 16078.

Most of the information contained in this paper was taken from C. Richard Edwards, FAO International Expert on Diabrotica, TCP/RER/6712(A), Terminal Report, Containment and Control of the Western Corn Rootworm in Europe, Food and Agriculture Organization of the United Nations, Plant Production and Protection Division, Plant Protection Service, Integrated Pest Management Group, March 5, 1999.

\section{Literature}

Baca, F. (1993): New member of the harmful entomofauna of Yugoslavia Diabrotica virgifera virgifera LeConte (Coleoptera: Chrysomelidae). IWGO News Letter, Vol. XIII, (1-2), 21-22.

Edwards, C. R. (1999): Containment and control of the western corn rootworm in Europe. Food and Agriculture Organization of the United Nations, Plant Production and Protection Division, Plant Protection Service, Integrated Pest Management Group, TCP/RER/6712(A), Terminal Report, March 5, 1999.

Edwards, C. R., Igrc Barcic, J., Berger, H. K., Festic, H., Kiss, J., Princzinger, G., Schulten, G. G. M. and Vonica, I. (1998): Overview of the FAO western corn rootworm management program for central Europe. Pflanzenschutzberichte Band 57, Heft 2, 3-14.

Musick, G. J. and Suttle, P. J. (1972): Ohio northern corn rootworm research, Part I: Chemical control. Annual Report. Ohio Agricultural Research and Development Center, Wooster, Ohio.

Tóth, M., Tóth, V., Újváry, I., Sivcev, I., Manojlovic, B. and Ilovai, Z. (1996): Sex pheromone trapping of Diabrotica virgifera in Central Europe. Növényvédelem, 32, 9, 447-452. 